\title{
México: los partidos políticos en la coyuntura electoral
}

$\mathrm{R}$

eflexionar sobre las elecciones hoy, obliga a referirnos a julio de 1988 en que se trastocaron tendencias y significados de los comicios en México.

Son muchas las novedades que se registraron entonces. Se habló de una insurgencia ciudadana y de un movimiento decidido en contra del gobierno y su partido, canalizados a través de dos grandes opciones políticas, el Partido de Acción Nacional (PAN) y el Frente Democrático Nacional (FDN). Las elecciones fueron realmente disputadas, la representación nacional efectivamente se pluralizó y la democratización política apareció como consigna insoslayable.
Los acontecimientos electorales posteriores nos muestran que muchas cosas han cambiado, pero que otras se empecinan en mantenerse inmutables.

En primer término, el calendario electoral parece haberse impuesto sobre el calendario político del país, lo cual da cuenta de la relevancia que han adquirido los comicios en México, no sólo para el gobierno y los partidos políticos, sino para la opinión pública en general. En efecto, muchas decisiones públicas parecen estar expuestas al desarrollo de los procesos electorales. Baste recordar la forma como se anunció el triunfo del candidato panista a la gubernatura de Baja California, mucho antes de la cali- 


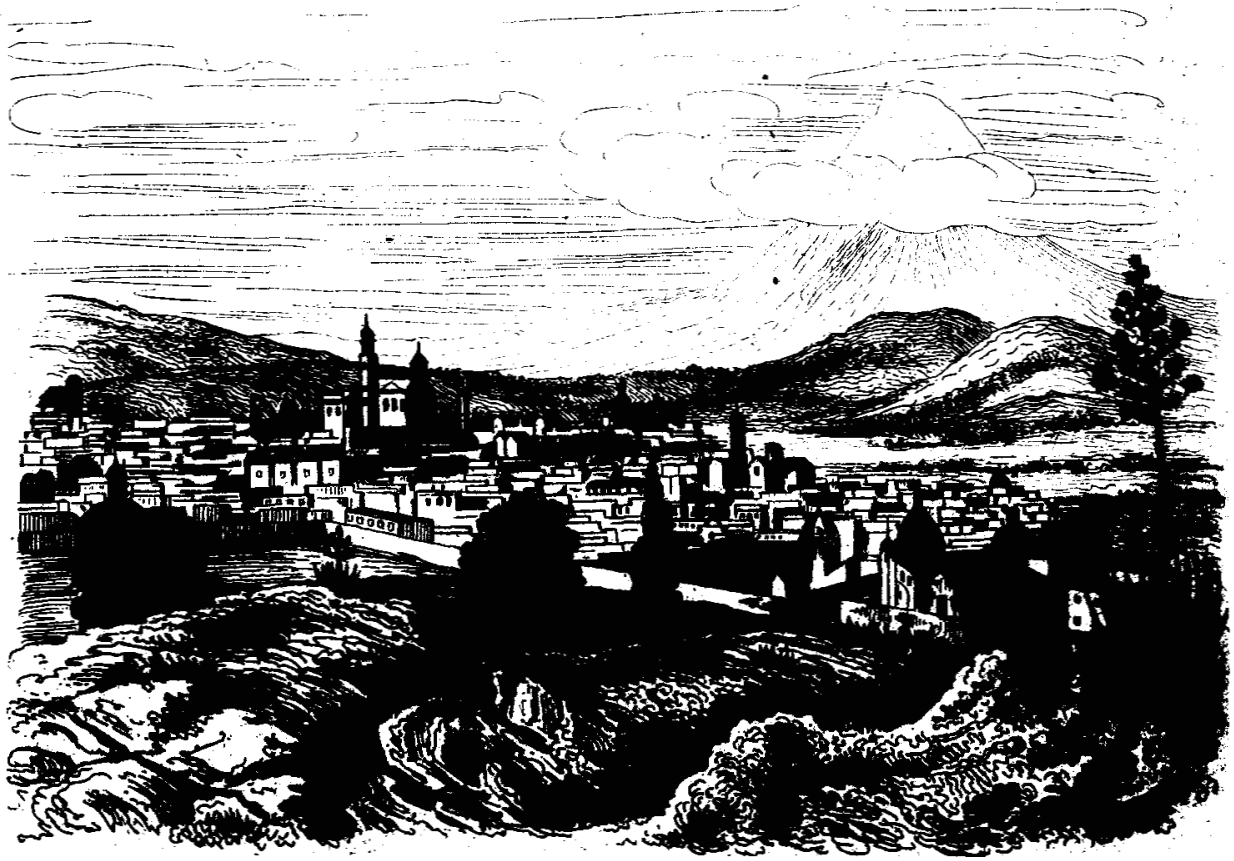

fiçación electoral, acción que buscaba servir de contrapeso a los conflictos que se avecinaban en Michoacán.

Por otra parte, las elecciones se han convertido en vehículos de expresión de demandas políticas. Hasta el inicio de los años ochenta la conflictiva política surgida de la expresión de demandas no se insertaba en el terreno electoral; ambos parecian correr paralelamente. Actualmente, la arena de los comicios se ha tornado en sitio de articulación de organizaciones y movimientos sociales otrora dispersos.

En cambio la competencia electoral que es un dato nuevo, no se ha generalizado, sino que continúa desigual y desequilibrada, ya que existen zonas donde las elecciones son verdaderos procesos reñidos, junto a muchas otras donde el Partido Revolucionario Institucional (PRI) no encuentra mayores obstáculos para triunfar. Además la competencia tiene raíces diferenciadas, aunque no excluyentes, pues en ocasiones refleja una reivindicación propiamente ciudadana y tal vez el surgimiento de una nueva cultura política más participativa, que es el caso de los grandes centros urbanos, mientras que en otras es más el resultado de un desgaste en los mecanismos tradicionales del partido del régimen, como en Michoacán y Guerrero. Uno y otro caso están atravesados por la gran inconformidad que existe frente al gobierno y su partido.

Los comicios tampoco han ganado credibilidad, es más, el hecho de que haya una oposición más fuerte no ha redundado en contiendas más transparentes, por el contrario: éstas aparecen cada vez más y con mayor certeza como desconfiables, justamente porque hay mejores condiciones para detectar la ma- 
nipulación del voto. El fraude sigue siendo una referencia obligada de cualquier opinión y análisis sobre las elecciones, así como de cualquier táctica de oposición. ${ }^{1}$

Es cierto que una sola contienda, por espectacular que resulte, dificilmente podrá modificar en lo sustancial los actores y procedimientos del quehacer político. La posibilidad de que la democratización prospere dentro de un marco de estabilidad política depende de que existan una verdadera voluntad política para impulsarla y, sobre todo, organizaciones sociales capaçes de conducirla.

En este sentido, el propósito de este trabajo es abordar el tema de la repercusión de las elecciones sobre los partidos políticos, en el entendido de que "un sistema democrático es básicamente, en términos de su operación, un sistema de partidos". ${ }^{2}$

Desdé la reforma política de 1977 que eliminó constreñimientos legales para la participación de los partidos políticos en la esfera electoral, ${ }^{3}$ las estrategias de los partidos han estado centradas en el camino de las umas. Los de izquierda, que antaño cifraban sus objetivos en insertarse en los grandes movimientos sociales o en la lucha de clases, han encontrado en las elecciones razones de primer orden no sólo para promover su unificación, sino para modificar sus estructuras y objetivos. Por otra parte, el

${ }^{1}$ Un destacado dirigente panista, Carlos Castillo Peraza, ha declarado que los partidos de oposición invierten muchos esfuerzos en intentar detectar el fraude.

${ }^{2}$ Giovanni Sartori, The theory of democracy revisited, Chatham House, N. Jersey, 1987, t. I, p. 148.

${ }^{3}$ Esta apertura representada por el registro condicionado fue temporal, ya que en 1987 el Código Federal Electoral lo canceló. ascenso del llamado "neopanismo" se ha fincado en el llamado a una acción electoral más agresiva como vía para acceder al poder y no sólo para construir la conciencia ciudadana como rezaban sus metas originales.

A mâs de un decenio de distancia y a casi dos años de la conmoción del 6 de julio, el panorama de los partidos como grandes sujetos electorales es desalentador y existen serios obstáculos para la constitución de un verdadero sistema de partidos.

Podemos convenir que los partidos políticos han cobrado importancia en la opinión pública nacional, lo cual permite que muchos identifiquen con claridad a las tres grandes fuerzas electorales, sin embargo, esto no es sinónimo de mayor prestigio social de los organismos partidarios y mucho menos de una reivindicación del sentido de la militancia. ${ }^{4}$ Tampoco se ha traducido en el desarrollo de su función parlamentaria que es clave para la proyección de una vida democrática. La presencia pluripartidista en la Cámara de Diputados, lejos de contribuir a dignificar la figura y función del diputado, ha abonado su desprestigio y en vez de reforzar al Congreso como instancia de deliberación por excelencia, ha amenazado frecuentemente con llevarlo a la parálisis.

Los tres grandes frentes electorales atraviesan hoy por una crisis doble: de integración de las distintas corrientes y tendencias que conviven en su seno, y de identidad, en términos de la falta de definición de sus grandes líneas ideológico-programáticas, en el contenido de

${ }^{4}$ El surgimiento del PRD levantó expectativas de un florecimiento de la militancia partidista. Sin embargo, al parecer éstas no se cumplieron, por lo que se prefirió aprovechar el registro del PMs para obtener el reconocimiento oficial del PRD. 
la transición política que vive nuestro país.

En el caso del PRI, el dato más conspicuo es la caída de su apoyo electoral y la pérdida del monopolio sobre los puestos de elección que nunca había tenido que compartir realmente con otros. Esto ha provocado tensiones en su interior reflejadas primero, en la escisión de 1987 que dio lugar a la formación de la Corriente Democrática motivada, como en el pasado, por la ausencia de espacios de participación en la toma de decisiones, particularmente en aquellas relativas a la selección del personal político.

-Empero, en esta ocasión, el desprendimiento ha sido irreductible 5 y la Corriente devino punta de lanza en la formación de un núcleo capaz de atraer y sumar a fuerzas de oposición partidarias y sociales.

Pero, la salida de la Corriente Democrática no ha solucionado las diferencias dentro del PRI. Hoy pueden identificarse dos grandes fracciones, denominadas popularmente los "dinos" y los "renos" que se disputan el control del aparato partidario. Mientras los primeros representan los intereses más arraigados dentro del Revolucionario Institucional -aquéllos ligados a la estructura corporativo-clientelista-, los segundos constituyen el grupo de renovación generacional, formado por los que no han pasado por la carrera partidaria, ajenos a las prácticas de movilización priísta tradicional y que promueven nuevos métodos de penetración en el tejido social. La gran paradoja es que los reformadores están ligados a la burocracia del ejecutivo -son de hecho más

\footnotetext{
${ }^{5}$ Los desprendimientos del partido oficial en 1940,1946 y 1952 no sobrevivieron a la contienda electoral que los vio nacer y muchos de sus miembros fueron reincorporados al sistema.
}

salinistas que priistas- y no a las estructuras del instituto político, con todo y que ocupan puestos de dirección en el Comité Ejecutivo Nacional.

Detrás de esta diferenciación más aparente, se esconden posturas distintas de mayor profundidad. Los reformadores 0 modernos postulan formas más centralizadas de mediación y representación que chocan con aquéllas cifradas en una vieja red de relaciones entre jefes o ca: ciques locales, líderes sindicales y burocracias políticas. ${ }^{6}$

La crisis de integración e identidad del PRI abarca su vinculación con el gobierno que es parte de su carácter intrínseco. En el curso de sus 60 años de vida, el partido de la revolución ha ido perdiendo peso frente al gobierno, de suerte que su imbricación con éste, que antes implicaba un intercambio de compromisos y beneficios, se ha ido transformando en sujeción plena. Las decisiones se adoptan en forma más centralizada y el aparato partidario se ha visto reducido a cumplir su función de control para hacer posible que dichas decisiones se traduzcan en acciones prácticas.

El caso de los pactos antiinflacionarios de los últimos tres años ejemplifica esta situación. Los gobiemos formularon y acordaron los Pactos de Solidaridad, primero y de Estabilidad y Crecimiento después y fue indispensable el aval corporativo, pero no para definir sus contenidos, sino para asegurar su realización.

Esta es quizá la contradicción más fuerte entre gobierno y partido, ya que

${ }^{6} \mathrm{Joe}$ Foweraker, "Popular movements and the transformation of the system", en Wayne Cornelius, Judith Gentleman, Peter Smith (comps.), Mexico's alternative political futures, Center for US-Mexican Studies, University of California, San Diego, 1989, p. 121. 


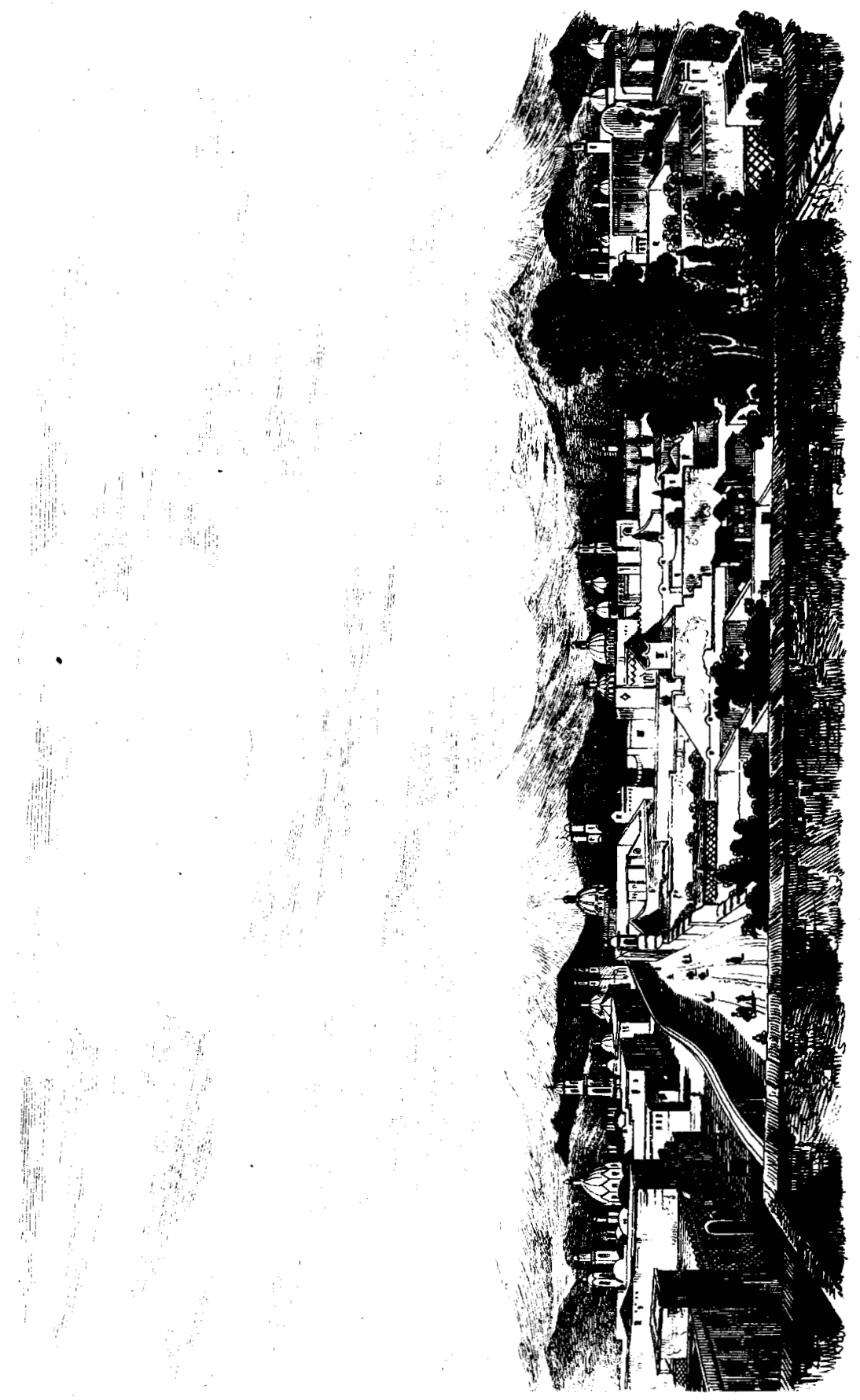


mientras aquél está empeñado en un proyecto económico que reclama el desmoronamiento de estructuras corporativas y cerradas, éstas siguen garantizando niveles básicos de control social. El PRI tal como está no sirve al gobierno y a sus afanes modernizadores, pero no puede librarse del aparato anquilosado. A finales de 1989 la aprobación de la miscelánea fiscal en la Cámara de Diputados reflejó las diferentes preocupaciones que guían al gobierno y al partido. La aplicación de un sistema impositivo de mayor cobertura alcanzaba a grupos que han sido tradicionalmente las clientelas electorales del partido.

El PRI se encuentra en un callejón sin salida: por un lado está obligado a renovarse, so pena de seguir perdiendo apoyo de un electorado cada vez más agraviado por sus excesos y de unas bases sociales crecientemente conscientes de la falta de representatividad de sus líderes formales; por otro, lanzarse de lleno a su transformación implica contribuir al desmoronamiento de quienes han sido agentes de control social y politico y por el momento no se vislumbran organizaciones capaces de sustituirlos. La incertidumbre sobre la dirección futura del partido oficial ha generado que se formen grupos como la Corriente Crítica, encabezada por Rodolfo González Guevara. Se trata de un movimiento que busca distinguirse de la Corriente Democratizadora por carecer de connotaciones caudillistas, es decir, no apuesta a la estatura política de los convocantes, sino a impulsar la participación de las filas priistas de su estructura directa y territorial. Su consigna ha sido promover el cambio a partir de reconocer que el presidente de la república es el líder indiscutible del PRI, y que por tanto, su anuencia es indispensable para que se realicen las reformas.
A pesar de que la Corriente Crítica ha logrado sobrevivir, su impacto dentro del partido ha sido prácticamente nulo. Es un grupo tolerado, hasta hoy sin cuota alguna de poder dentro del partido, pero el hecho de que sus pronunciamientos recojan demandas latentes dentro de las filas partidistas explica por qué la directiva lo ha contemplado como una piedra en el camino, en vez de como un sostén para el cambio.

Unos y otros reconocen el imperativo del cambio del PRI, sin embargo no han arribado a acuerdos sobre la profundidad y los contenidos del mismo. Además, como siempre, lo inmediato se impone a lo importante. La XIV Asamblea Nacional, señalada como el evento para la definición de los rumbos del partido desde el inicio del gobierno salinista, fue aplazándose durante casi dos años, a falta de consenso en torno a los lineamientos del cambio, pero también en espera de que se defina la nueva legislación electoral que deberá aprobarse durante el tercer periodo ordinario de sesiones de la actual Legislatura.

Las fechas y los temas de la que será la asamblea del cambio fueron finalmente anunciadas por el presidente Salinas en la celebración del LXI Aniversario del Tricolor. Las seis propuestas salinistas: 1) selección democrática de los candidatos a puestos de elección; 2) reconocimiento de las diferentes corrientes; 3) claridad en el origen de los recursos; 4) autonomía de las instancias del partido frente a las autoridades públicas; 5) formación de cuadros partidarios y 6) compromiso con el debate de los grandes problemas nacionales, implican modificaciones sustantivas para el Revolucionario Institucional.

Independientemente de que están aún por definirse los mecanismos específicos para la puesta en marcha de las 
reformas, persisten interrogantes claves, como cuáles van a ser las funciones y espacios de las corporaciones y cómo se va a lograr transformar al PRI de partido de gobierno a partido en el gobierno.

El hecho mismo de que fuera el presidente de la república quien echara a andar el proceso tan anunciado, refleja la atadura del partido al titular del ejecutivo y las grandes dificultades que existen para que logre eventualmente autonomizarse del poder y convertirse finalmente en un partido político en sentido estricto. $^{7}$

La segunda fuerza electoral, el PAN, que ha sido el partido de la oposición más consistente, atraviesa también por una situación crítica que fue gestándose a lo largo del decenio de los ochenta y que se agravó después de las elecciones federales de 1988, concretamente a raíz del apoyo que su directiva otorgó al dictamen prísta sobre las modificaciones constitucionales en materia electoral, en octubre de 1989.

Desde la postulación de Manuel J. Clouthier a la presidencia de la república, la fracción moderna dentro del blanquiazul, conocida como neopanismo, se hizo hegemónica, desplazando a segundo término a la fracción defensora de los principios de doctrina y objetivos tradicionales del partido, lo cual se evidenció posteriormente en la composición del llamado gabinete paralelo que quedó prácticamente en manos de los

\footnotetext{
${ }^{7}$ Las teorias sobre partidos políticos enfatizan distintas características que deben satisfacer; sin embargo, concuerdan en que son órganos que confeccionan votos, los traducen en representación política y están encaminados a la conquista del poder: Véanse los textos clásicos de Maurice Duverger, Los partidos politicos, FCE, 1957; Sigmund Neumann, Partidos politicos modemos, Tecnos, 1971; Giovanni Sartori, Partidos y sistemas de partidos, Alianza Universidad, 1976, t. 1.
}

allegados al ex dirigente empresarial y al presidente del Comité Ejecutivo $\mathrm{Na}$ cional, Luis H. Álvarez. ${ }^{8}$

A la llegada de Salinas al poder, la directiva panista promovió el diálogo con el presidente que derivó en reuniones mensuales, vistas con recelo por parte de algunos de los "tradicionalistas" ya que consideraban que se empañaba la línea opositora de Acción Nacional.

El voto de confianza del PAN al gobierno, plasmado en la famosa "carta de intención" que apuntaba las bases y criterios fundamentales que deberían respetarse en la elaboración de la ley electoral, ${ }^{9}$ hizo que afloraran a la luz pública las cuentas pendientes entre las dos grandes tendencias dentro del partido. Sin embargo la polémica reflejó la fuerza del pasado en Acción Nacional. Cuando el PAN parecía acercarse a remontar su carácter de oposición moralista o testimonial para erigirse en auténtica oposición política, su pasado cobró revancha y los argumentos esgrimidos fueron más moralistas que políticos.

Los "tradicionalistas" acusaban a los dirigentes por haber pactado con el "enemigo" y éstos se defendían reclamándoles que hubiesen ventilado la discusión más allá de las fronteras del partido.

La pugna se extendió a febrero de 1990 , en la Convención Nacional para el relevo de los dirigentes. Los "tradicionalistas" se rehusaron a apoyar la

\footnotetext{
${ }^{8}$ Quizá el concepto de "neopanistas" contrapuesto al de los "tradicionalistas", noes el más pertinente porque muchos de sus dirigentes originales como González Schmal, Pablo Emilio Maderoo Conchello, ahora son miembros destacados de la fracción que impugna a la directiva moderna. Sin embargo se utilizan porque son referencias muy reconocidas.

${ }^{2} \mathrm{La}$ "carta de intención" fue publicada en La Jomada, el 21 de octubre de 1989, p. 12.
} 
reelección de Luis $H$. Álvarez y se lanzaron a promover la candidatura de Gabriel Jiménez Remus, pero una vez que Álvarez fue ratificado, el nuevo Comité Ejecutivo sólo conservó a un miembro del grupo crítico, es decir, respondió con una medida excluyente que abonó el terreno del enfrentamiento interno.

Un mes después se constituyó el Foro Democrático y Doctrinario como expresión de la voluntad del grupo desplazado de no cejar en su propósito de consolidarse como corriente de opinión dentro del partido, lo que de nueva cuenta llevó a los dirigentes a insinuar que se consideraría la posible expulsión de los detractores. Esto condujo posteriormente a que se acusara a miembros del Comité Ejecutivo por haber aceptado ayuda financiera de fundaciones extranjeras, lo cual se convirtió en un verdadero escándalo que aprovecharon partidos co- mo el Partido Popular Socialista (PPS) que solicitó incluso el retiro del registro del PAN, para eliminar a un contendiente.

Acusaciones como ésta tienen distintas repercusiones: alimentan el descrédito de los partidos políticos y actitudes persecutorias que en nada ayudan a la consolidación del sistema de partidos. Empero, para Acción Nacional puede significar la oportunidad para replantear su integración interna desde una pers-: pectiva más tolerante y de colaboración entre sus diversas tendencias.

Por otra parte, la defensa de una política gradualista y de diálogo con el gobierno, que se postuló en el contexto de la reforma electoral después de los triunfos inéditos de Acción Nacional, plantea la interrogante de dónde están las apuestas actuales del partido blanquiazul. Se opta, o bien por consolidar la base electoral con la que ya cuenta y
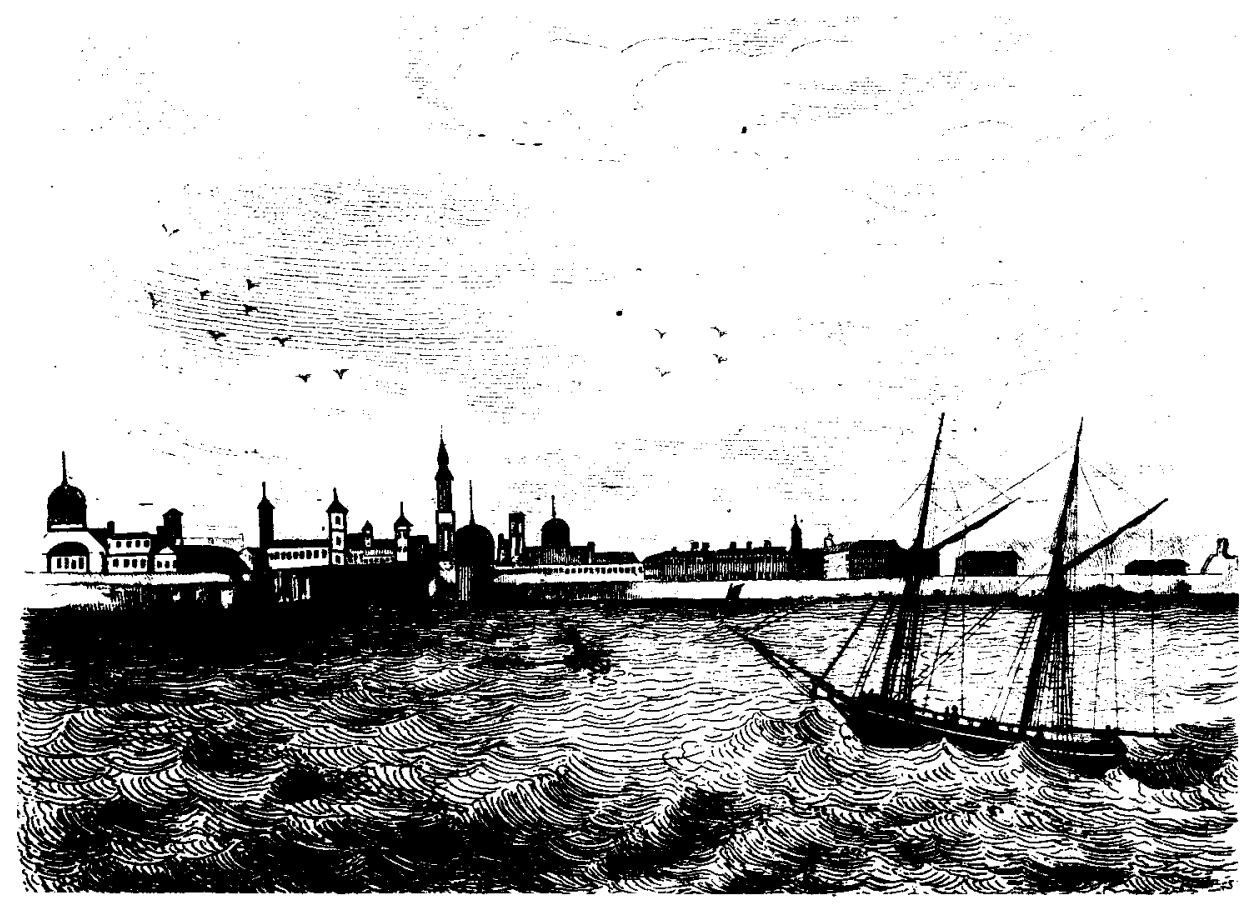
que, más que por identificación con su doctrina y programas se debe a su consistente posición crítica e independiente frente al PRI y el gobierno, o bien se buscan lineas de entendimiento con el poder como método para avanzar, que aunque nuevas para el PAN, son técnicas muy arraigadas en nuestra cultura política. ${ }^{10}$

Por último, la situación del Partido - de la Revolución Democrática (PRD) es quizá la más grave, sobre todo porque muchas de las expectativas de democratización se cifraron en él.

Las reflexiones sobre el PRD deben considerar que es un partido con un año escaso de vida pero que nació con un gran peso encima, como es el de impulsar la transición democrática, y que se fincó sobre equilibrios muy frágiles entre los distintos grupos que lo integraron.

La formación del Frente Democrático Nacional (FDN) en vísperas de la contienda federal de 1988 significó un impulso unificador de formaciones partidarias, organizaciones y movimientos políticos, mas no por el encuentro de proyectos, sino por la figura que lo encabezaba.

Es cierto, no obstante, que había un objetivo común: golpear al gobierno y a su partido, aunque las motivaciones y los cálculos de la intención eran distintos. Los tres partidos tradicionalmente aliados, más del gobierno que del PRI, el PPS, el Partido Auténtico de la Revolución Mexicana (PARM) y el Partido del Frente Cardenista de Reconstrucción Nacional

${ }^{10} \mathrm{El}$ entendimiento con el poder ha probado ser de gran provecho para los llamados paraestatales. Primero les permitió llegar a diputados de partido sin tener $2.5 \%$ de los votos y después beneficiarse, a costa de los partidos de oposición más fuertes, con la fórmula electoral de la primera proporcionalidad.
(PFCRN), hallaron la posibilidad de ganar mayor capacidad de presión frente a su aliado, quizá para condicionar futuros apoyos. Para el Partido Mexicano Socialista (PMS), que sólo tardiamente pactó con la Corriente Democrática, su apoyo a la candidatura de Cárdenas fue una fase más del proceso iniciado a principios de los ochenta, encaminado a promover una línea amplia de izquierda por la vía electoral. ${ }^{11}$

Terminado el proceso electoral que trastocó la ubicación de los partidos ligados al FDN en el espectro partidario mexicano (el PFCRN se convirtió en la tercera fuerza electoral y el PMs la perdió después de diez años de poseerla, para descender a la sexta y última posición), la necesidad de convertir al movimiento cardenista en un partido mostró la fragilidad del entendimiento entre las partes.

Sólo el PMS se dispuso a integrarse cabalmente al PRD, pero de todas maneras no se han borrado las diferencias entre sus distintas corrientes. La figura de Cárdenas ha sido el único elemento, más que de reconciliación, de disciplina interna, lo cual es una muestra de la debilidad orgánica del partido.

El PRD enfrenta el reto de reconciliar su reclamo de ser heredero legítimo de la tradición revolucionaria mexicana, con el de construir un nuevo flanco de la izquierda.

Otro de sus problemas es que, por una parte postula como meta suprema la instauración de la democracia política, con lo cual mira hacia adelante, pero, por otra, convoca al rescate de reivindicaciones.pasadas que fueron banderas de los gobiernos anteriores y ello difi-

"La fundación del pMs en 1987 postuló claramente la decisión de impulsar la convivencia de múltiples corrientes que podrian abarcar incluso a priistas progresistas.

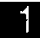

9 
culta la elaboración de un proyecto bien armado de cara al futuro.

El PRD ha centrado muchas de sus acciones en la ilegitimidad de origen del gobierno, más que en la posibilidad de afianzar los logros que sin duda alguna ha alcanzado, no solamente en términos de triunfos electorales, sino de presencia en la sociedad. Da la impresión de que el PRD tiene una especie de vocación maximalista, a la cual se ciñen todos sus actos. Sostiene que la alternancia es la prueba última de democracia, cuando ésta no ha sido en nuestro país garantia de respeto estricto a la voluntad popular, que sí es signo inequívoco de democracia política.

Muchas de las soluciones a litigios electorales entre el PRI y el PRD se han resuelto en las mesas de negociación entre cúpulas, que no en el recuento preciso y justo de los votos. De otra parte se ha apostado a la amenaza del enfrentamiento como vía para ganar posiciones, aunque esto es explicable en buena medida por el acoso permanente que el poder ejerce sobre el Partido de la Revolución Democrática.

El PRI está enfrascado en recuperar terreno, pero sus estimaciones de que lo logrará gracias a las dificultades internas del PRD denotan una visión estrecha e inmediatista del problema. Lo que ha probado el PRD es que en México subyace una masa latente de inconformidad social que de no encontrar cauces institucionales que le sirvan de válvula de escape, puede eventualmente encontrar salida a través de la violencia.

Es cierto que no todas las instituciones políticas se encuentran en situación crítica; durante el gobierno salinista la presidencia ha recuperado capacidad de convocatoria y credibilidad frente a la opinión pública nacional y extranjera. Sin embargo, si esta relativa dignificación de la presidencia no va acompanada del reforzamiento de instituciones partidarias, podemos perfilarnos hacia una refuncionalización del autoritarismo, más que a una verdadera transición a la democracia.

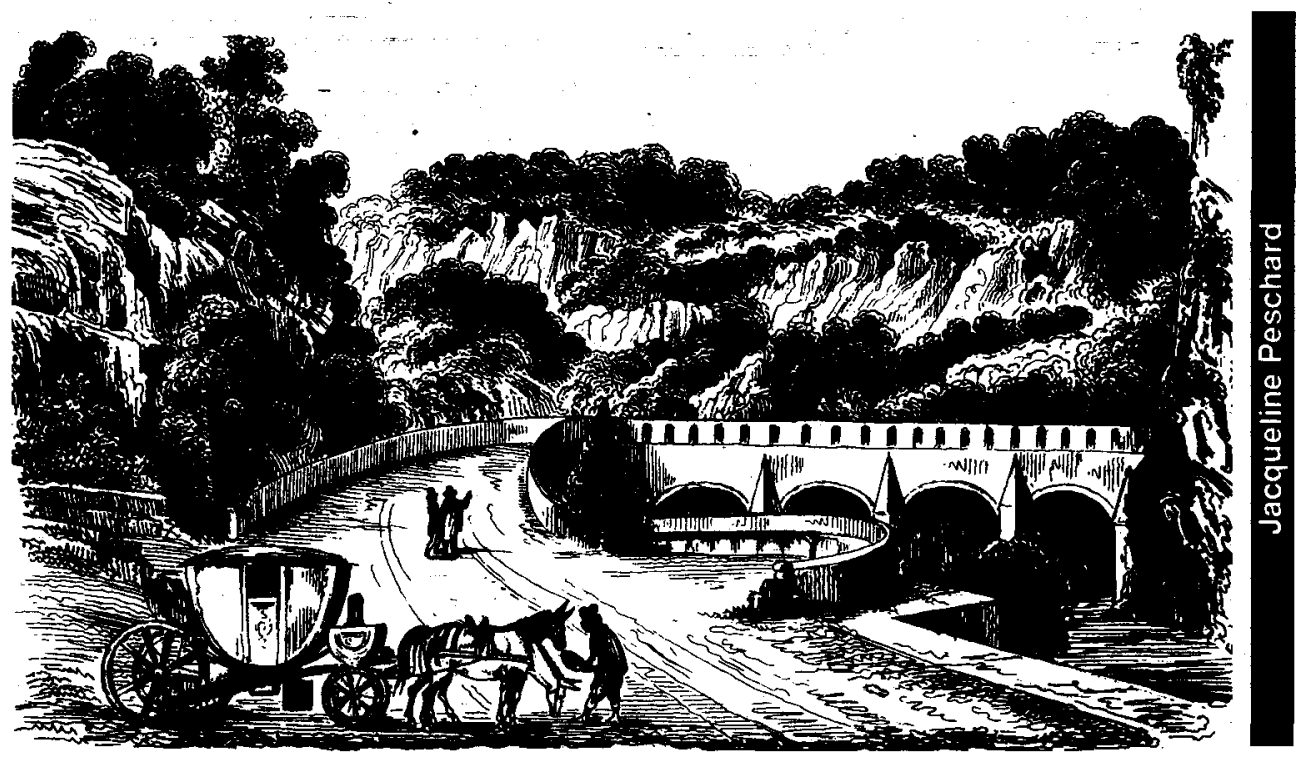

